UDC $543.062-3: 546.76^{\prime} 261-3: 669.141 .241 .4-122.4-415: 669.15^{\prime} 26-194.2$

\title{
低クロム含有リムド鋼中のクロム化合物の形態についで
}

\author{
川村和郎 ${ }^{* *}$. 伊藤英明 $* *$. 大坪孝至 ${ }^{* *} \cdot$ 田辺富夫**

\section{On the Formes of Chromium Compounds in Rimmed Steel with Low Chromium Content}

\author{
Kazuo KaWamura, Hideaki Iтo, \\ Takashi OTsubo, and Tomio TANABE
}

Synopsis:

An investigation has been made of the forms of chromium compounds in hot-rolled rimmed steel sheets containing $0.02 \sim 0 \cdot 1 \% \mathrm{Cr}$.

The results observed are summarized as follows:

(1) Besides chromium in solid solution, chromium was identified both in oxide, ( $\mathrm{FeMn}_{\text {) }} \mathrm{O} \cdot \mathrm{Cr}_{2} \mathrm{O}_{3}$, which is coarse particle, and sulfide, $\mathrm{FeS} \cdot \mathrm{Cr}_{2} \mathrm{~S}_{3}$, which is fine particle, and no chromium and carbide and nitride were found.

(2) The amount of $(\mathrm{FeMn}) \mathrm{O} \cdot \mathrm{Cr}_{2} \mathrm{O}_{3}$ increases in proportion to the increase in total $\mathrm{Cr}$ content while the amount of $\mathrm{FeS} \cdot \mathrm{Cr}_{2} \mathrm{~S}_{3}$ is determined mainly by sulfur content regardless of chromium content.

(Received Nov. 17, 1972)

\section{1. 緒言}

鋼中でのクロム系析出物としては炭化物, 酸化物, 窒 化物および硫化物などがあり，これらのうち炭化物につ いてはクロムが有力な炭化物形成元素ということで比較 的クロム添加量の多い鋼種についてはステンレス鋼に至 るまでの広範囲にわたつて研究がなされており，これら に関する報告も数多くみられる. いつぽう0.1\%以下の 低クロム鋼についての報告に関しては，炭化物以外のも のも含めてほとんどみあたらない3). 今回著者らはこの 低炭素低クロムからなるリムド鋼熱延薄鋼板中のクロム について, その鋼中に存在する化学種, 形状およびその 分離法などについて検討したので以下に報告する.

\section{2. 実 験方 法}

\section{$2 \cdot 1$ 供試料}

供試料は Table 1 に示したクロム量を種々変えた 4 種類で $2 \cdot 3 \mathrm{~mm}$ 厚に圧延したリムド鋼板を用いた.

Table 1. Chemical composition of samples (\%).

\begin{tabular}{c|c|c|c|c|c|c} 
& \multicolumn{1}{|c|}{$\mathrm{Cr}$} & $\mathrm{C}$ & $\mathrm{S}$ & $\mathrm{O}$ & \multicolumn{1}{c}{} \\
\cline { 1 - 3 } No 1 & 0.022 & 0.045 & 0.015 & 0.019 & $\mathrm{Si}$ & $<0.01$ \\
No 2 & 0.059 & 0.031 & 0.011 & 0.027 & $\mathrm{Mn}$ & 0.30 \\
No 3 & 0.077 & 0.036 & 0.015 & 0.028 & $\mathrm{~N}$ & 0.0025 \\
No 4 & 0.12 & 0.039 & 0.012 & 0.050 & $\mathrm{Al}$ & 0.006 \\
\hline
\end{tabular}

\section{$2 \cdot 2$ 析出物の分離法}

電解法……5\% クエン酸ナトリウム，1\% 真化カリウ ムから成る中性電解液による定電流電解 $\left(10 \mathrm{~mA} / \mathrm{cm}^{2}\right)$

沃素メタノ一ル溶解法.......14\% 沃素メタノール 溶液 による室温溶解

過塩素酸溶解法……10\% 過䘏素酸による $60^{\circ} \mathrm{C}$ 恒温 溶解

\section{3 分離残查の定典法}

分雖残査を硝酸, 硫酸, リン酸から成る混酸で加熱分 解し，これより一定量を分取してそれぞれつぎの方法に より定量した.

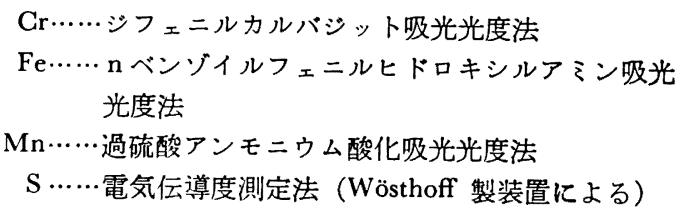

\section{3. 実 験 結 果}

\section{1 析出物の分離}

Table 1 の試料について電解法, 沃素メタノール溶解 法および過塩素酸溶解法でそれぞれ処理し，不溶解残査 中のクロム量を定量して Table 2 に示した.

* 昭和 47 年 11 月 17 日受付

** 新日本製鉄(株)製品技術研究所 
Table 2. Aralytical results of chromium in the residues separated by various dissolution methods $(\%)$.

\begin{tabular}{l|c|c|c|c}
\hline & No 1 & No 2 & No 3 & No 4 \\
\hline Electrolysis & 0.001 & 0.005 & 0.013 & 0.051 \\
$\mathrm{I}_{2}-\mathrm{CH}_{3} \mathrm{OH}$ & 0.002 & 0.007 & 0.014 & 0.051 \\
$10 \% \mathrm{HCLO}_{4}$ & 0.001 & 0.007 & 0.014 & 0.051 \\
\hline
\end{tabular}

析出物の分離法を検討する場合，一般に電解法を基準 にするという考え方がとられており，クロム系析出物に ついてもこの考え方が十分適用しうるものと思われる.

したがつて Table 2 の結果で各溶解法の間に差異がみ られないことから，クロム系析出物はすべて分離されて いると判断される. そこで 以下過塩素酸溶解法により Table 1 の試料を処理することとした. なおこの方法に よればクロム系析出物以外のもの，たとえば $\mathrm{MnS}$ など が除去されるという利点がある．この方法により試料を 処理し，その不溶解残查中の $\mathrm{Fe}, \mathrm{Mn}, \mathrm{Cr}$ およ゙ $\mathrm{S}$ を 定量して Fig. 1 を得た. Fig. 1 は試料中のクロム量と 不溶解残査中の各元素についての定量值を対比させたも のである.なお同様に処理して得た不溶解残査中の窒素 を定量したが，いずれの試料からも検出されなかつた.

\section{2 析出物の同定}

過塭素酸溶解法による不溶解残查を $\mathrm{X}$ 線回折したと ころ, Table 3 に示すようなスピネル構造のパターンが 得られた.

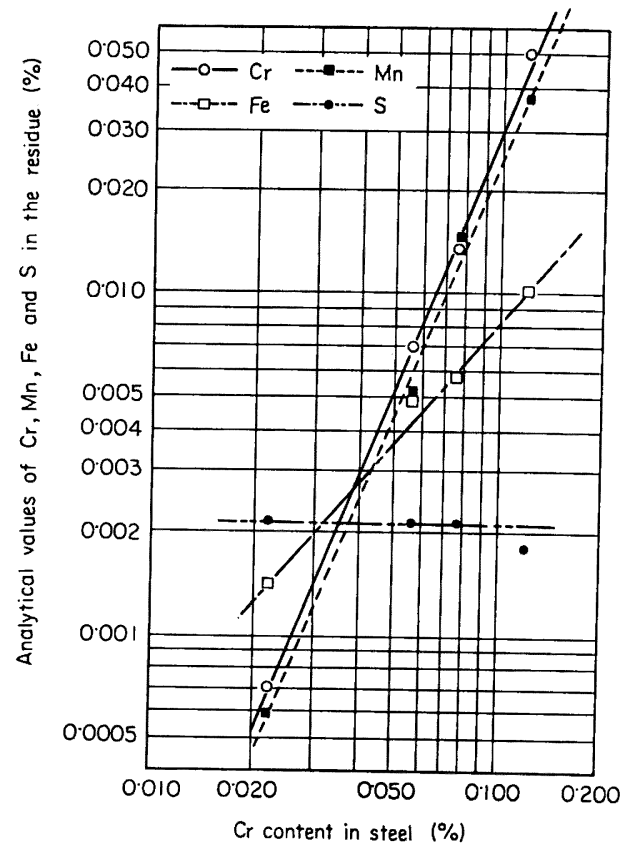

Fig. 1. Analytical results of the residues separated by dissolution with perchloric acid.

いつぽうこの不溶解残査を電子顕微鏡で観察すると, すべての試料について粒子の大きさが $1 \mu$ 以下の微細な ものと $10 \mu$ 以上の大きなものとの 2 種類に分けられ,

Table 3. Results of X-Ray diffraction of the residue separated by dissolution with perchloric acid.

\begin{tabular}{|c|c|c|c|c|c|c|c|}
\hline \multirow{2}{*}{\multicolumn{2}{|c|}{$\mathrm{X}$-Ray diffraction }} & \multicolumn{6}{|c|}{ A S TM } \\
\hline & & \multicolumn{2}{|c|}{$\mathrm{FeO} \cdot \mathrm{Cr}_{2} \mathrm{O}_{3} *$} & \multicolumn{2}{|c|}{$\mathrm{FeS} \cdot \mathrm{Cr}_{2} \mathrm{~S}_{3} * *$} & \multicolumn{2}{|c|}{$\mathrm{FeS} \cdot \mathrm{Cr}_{2} \mathrm{~S}_{3} * * *$} \\
\hline \multirow{2}{*}{$\begin{array}{c}(d \AA) \\
4 \cdot 88 \\
3 \cdot 52\end{array}$} & \multirow{2}{*}{$\begin{array}{c}(I \text { obs.) } \\
\mathrm{M} \\
\mathrm{W}\end{array}$} & \multirow[t]{2}{*}{$\begin{array}{c}(d \AA) \\
4 \cdot 83\end{array}$} & \multirow{2}{*}{$\begin{array}{c}\left(I / I_{1}\right) \\
(50)\end{array}$} & $(d \AA)$ & $\left(I / I_{1}\right)$ & $(d \AA)$ & $\left(I / I_{1}\right)$ \\
\hline & & & & $3 \cdot 53$ & $(80)$ & \multirow{3}{*}{$\begin{array}{l}3 \cdot 54 \\
3 \cdot 35 \\
3 \cdot 02 \\
2 \cdot 91\end{array}$} & \multirow{3}{*}{$\begin{array}{r}(40) \\
(40) \\
(100) \\
(20)\end{array}$} \\
\hline \multirow{3}{*}{$\begin{array}{l}2 \cdot 97 \\
2 \cdot 91 \\
2 \cdot 87 \\
2 \cdot 53 \\
2 \cdot 50 \\
2 \cdot 29\end{array}$} & \multirow{4}{*}{$\begin{array}{l}\text { S } \\
\text { VW } \\
\text { VW } \\
\text { VS } \\
\text { M } \\
\text { VW }\end{array}$} & \multirow[t]{2}{*}{$2 \cdot 95$} & \multirow[t]{2}{*}{$(50)$} & $3 \cdot 01$ & $(100)$ & & \\
\hline & & & & $2 \cdot 87$ & $(40)$ & & \\
\hline & & $2 \cdot 51$ & $(100)$ & $\begin{array}{l}2 \cdot 50 \\
2 \cdot 29\end{array}$ & $\begin{array}{l}(80) \\
(40)\end{array}$ & \multirow{2}{*}{$\begin{array}{l}2 \cdot 51 \\
1 \cdot 95 \\
1 \cdot 93\end{array}$} & $(60)$ \\
\hline \multirow{4}{*}{$\begin{array}{l}1 \cdot 91 \\
1 \cdot 76 \\
1 \cdot 70 \\
1 \cdot 62 \\
1 \cdot 61\end{array}$} & & \multirow{2}{*}{$1 \cdot 91$} & \multirow{2}{*}{$(75)$} & & & & $\begin{array}{l}(40) \\
(60)\end{array}$ \\
\hline & \multirow{3}{*}{$\begin{array}{l}\mathrm{S} \\
\mathrm{W} \\
\mathrm{M} \\
\mathrm{M} \\
\mathrm{S}\end{array}$} & & & $\begin{array}{l}1 \cdot 92 \\
1 \cdot 77\end{array}$ & $\begin{array}{r}(80) \\
(100)\end{array}$ & \multirow{3}{*}{$1 \cdot 77$} & \multirow{3}{*}{$(100)$} \\
\hline & & $1 \cdot 71$ & (25) & $1 \cdot 69$ & $(40)$ & & \\
\hline & & $1 \cdot 61$ & (75) & & & & \\
\hline $1 \cdot 49$ & $\mathbf{M}$ & $1 \cdot 49$ & $(75)$ & $1 \cdot 58$ & $(60)$ & & \\
\hline
\end{tabular}

* ASTM 4-0759 $\mathrm{MoK}_{\alpha} \lambda=0 \cdot 70926$

** ASTM 4-0615 $\mathrm{CrK}_{\alpha} \lambda=2 \cdot 2909$

*** ASTM 3-1113 $\mathrm{FeK}_{\alpha} \lambda=1 \cdot 93597$ 


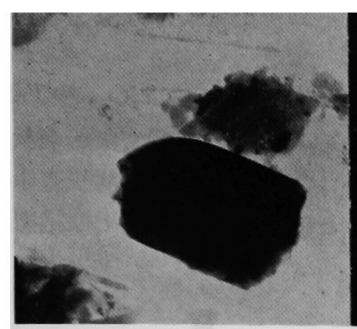

a )

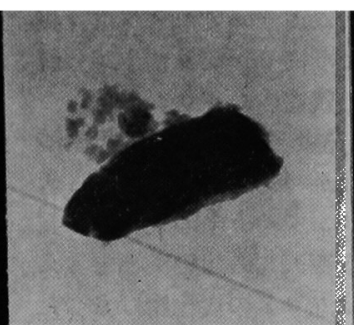

b )

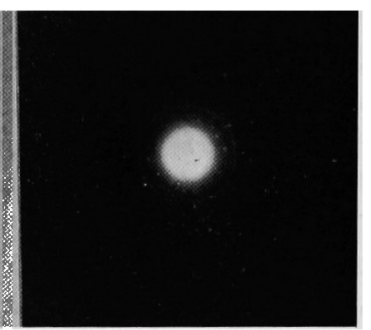

a) separated by dissolution with perchloric acid. $(\times 10000)$
b) separated by electrolysis. $(\times 20000)$

Photo. 1. Electron micrographs of $\mathrm{FeS} \cdot \mathrm{Cr}_{2} \mathrm{~S}_{3}$.

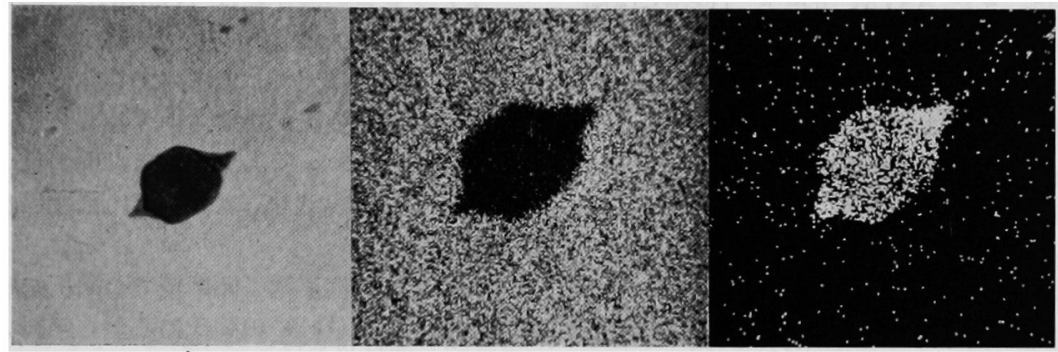

a)

b)

c)

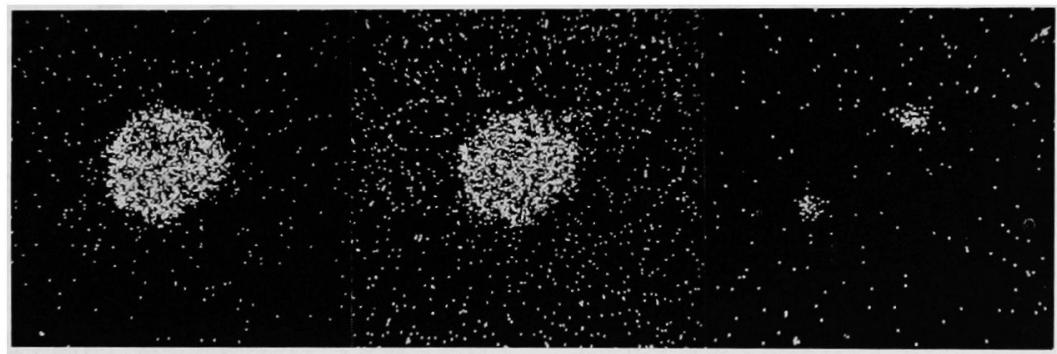

d)

e )

f)

a) optical micrograph. $(\times 600)$

b) f) Images of characteristic $X$-rays of each elements existing in chromium oxides investigated by XMA.

b) $\mathrm{FeK}_{\alpha}$ c) $\mathrm{MnK}_{\alpha}$ d) $\mathrm{CrK}_{\alpha}$ e) $\mathrm{O}_{2} \mathrm{~K}_{\alpha}$ and f) $\mathrm{SK}_{\alpha}$.

Photo. 2. Chromium Oxides observed in a cross-section of sample.

この中間のものはほとえどないか，あるいはわずかであ つた.これらのうち大きいものはすべて電子線回折は不 可能であつたが，微細なものについてはその 1 例を Photo. 1 に示すように $\mathrm{FeS} \cdot \mathrm{Cr}_{2} \mathrm{~S}_{3}$ であることを確認し た.なおこのものは当所の $200 \mathrm{KV}$ 電子顕微鏡では同定 しえず, 日本電子（株）の $1000 \mathrm{KV}$ 超大型電子顕微鏡 にて同定した. また電解残査の電子線回折からも同様の ものを確認したが，硫化物以外のクロム系析出物はなえ ら認められなかつた.

No 2 の試料についてその断面を研摩すると Photo. 2 a)に示したような析出物が多数観察される.これをX 線マイクロアナライザーで走査した結果, Photo. 2 b) 〜f）に示したように外側が硫化マンガンでおおわれた $\mathrm{Fe}, \mathrm{Mn}$ および $\mathrm{Cr}$ から成る酸化物であることがわかつ た.

\section{4. 考察}

一般にクロムは鋼中において鉄と固溶しているものと 種々の形状および化学種をもつて析出しているものとに 区分される. そして析出物としては炭化物, 酸化物, 窒化 物および硫化物などがあつて，これらがその鋼の組成な どにより何種類かが同時に析出していると考えられる. 今回著者らが検討したりムド鋼熱延薄鋼板ではこれらの うち硫化物と酸化物を確認した. 
（1）電解残査の電子線回折によりセメンタイトを確 認したが, Table 2で示したようにセメンタイトが分解 しないような電解法で分離した残查中のク口ム量と，セ メンタイトが分解するような赫酷な条件下での過塩素酸 溶解法でのそれとの間に差がなかつたてとと，クロム含 有量 $0 \cdot 1 \%$ 程度の鋼中でのセメンタイト中のクロム濃度 はせいぜい $0.5 \%$ であるという西沢らの報告1)とを考え あわせると，今回の試料中にはクロムの炭化物はまつた くないか，またたとえセメンタイトに溶解していたとし てもその量は無視しうる程度の量であると考えられる.

(2) 硫化物については電解観察により $\mathrm{FeS} \cdot \mathrm{Cr}_{2} \mathrm{~S}_{3}$ を 確認した (Photo. 1). なお CrSについてはその存在を 確認できなかつた．また ASTM カード $\left(\mathrm{FeS} \cdot \mathrm{Cr}_{2} \mathrm{~S}_{3}\right)$ に記載されている測定数值の背景については交献が入手 できず，不明である.

（3）酸化物については X 線回折の結果 (Table 3) と X 線マイクロアナライザーでの結果 (Photo. 2 ) か らマンガンを含んだ鉄クロマイト $(\mathrm{FeMn}) \mathrm{O} \cdot \mathrm{Cr}_{2} \mathrm{O}_{3}$ と 考えられる.

（4）楖原らは2) ク口ムの窒化物 $\mathrm{CrN}, \mathrm{Cr}_{2} \mathrm{~N}$ は $10 \%$ 過塩素酸により分朔されると報告しており，今回の著者 らの分離条件でも，むしこれら窒化物が存在するならば 分離されていることになるが，乙かし不溶解残查中から 室素が検出されなかつたこと, および電顕観察でも認め られなかつたことから，これら窒化物は存在しないもの と判断される.

（5） クロムの酸化物は試料中のクロム量に比例して 増加しているが，いつぽうクロムの硫化物はクロム量に
関係なく, 硫黄量によつてその析出量がほぼ決まるもの と考えられる(Fig. 1).

(6) 今回の検討により ( $\mathrm{Fe} \cdot \mathrm{Mn}) \mathrm{O} \cdot \mathrm{Cr}_{2} \mathrm{O}_{3}$ と $\mathrm{FeS}$. $\mathrm{Cr}_{2} \mathrm{~S}_{8}$ を確認したが，これらの量的な把握すなわち状態 別定量分析法は確立しなかつた. しかし不溶解残査中の $\mathrm{S}$ 量と $\mathrm{Cr}$ 量を定量することにより，おおよその把握は 可能となろう.

\section{5. 結}

\section{言}

リムド鋼熱延薄鋼板中のクロムについて検討し, 以下 の知見を得た。

1) クロムの炭化物および窒化物は認められなかつた

2) クロムの酸化物は $(\mathrm{FeMn}) \mathrm{O} \cdot \mathrm{Cr}_{2} \mathrm{O}_{3}$ の形で存在 し，その大きさは 10〜20 $\mu$ であつた.また析出量は鋼 中のクロム量に比例して増大する.

3) クロムの硫化物は $\mathrm{FeS} \cdot \mathrm{Cr}_{2} \mathrm{~S}_{3}$ の形で存在し, その 大きさは $1 \sim 2 \mu$ であつた. また析出量は鋼中の硫黄量 によつてほぼ決まり，クロム量には関係がないようであ る.

おわりに超高圧電子顕微鏡での回折を快くご承諾下さ つた日本電子(株)の田岡氏に心から感謝いたします.

\section{文献}

1) 西沢泰二, 佐藤知雄: 日本金属学会誌, 19 (1955), p. 385

2 ）柳原 正, 俣野宣久, 福田 豊: 日本金属学会誌 27 (1963), p. 152

3 ）若松茂雄：鉄鋼協会第 84 回講演大会討論会講演 (討論会譜演概要 ' $72-\mathrm{Al} 40$ ) 